\title{
THE
}

\section{Tomato Yellow Leaf Curl Virus Infection Alters Bemisia tabaci MED (Hemiptera: Aleyrodidae) Vulnerability to Flupyradifurone}

Baiming Liu

Evan L. Preisser

University of Rhode Island, preisser@uri.edu

Xiaoguo Jiao

Youjun Zhang

Follow this and additional works at: https://digitalcommons.uri.edu/bio_facpubs

The University of Rhode Island Faculty have made this article openly available. Please let us know how Open Access to this research benefits you.

This is a pre-publication author manuscript of the final, published article.

Terms of Use

This article is made available under the terms and conditions applicable towards Open Access Policy Articles, as set forth in our Terms of Use.

\section{Citation/Publisher Attribution}

Liu, B., Preisser, E. L., Jiao, X., \& Zhang, Y. (2020). Tomato Yellow Leaf Curl Virus Infection Alters Bemisia tabaci MED (Hemiptera: Aleyrodidae) Vulnerability to Flupyradifurone. Journal of Economic Entomology, 113(4), 1922-1926. https://doi.org/10.1093/jee/toaa118

Available at: https://doi.org/10.1093/jee/toaa118 
1

8

14

$17 U S A$

18
Youjun Zhang

Department of Entomology

Institute of Vegetables and Flowers

Chinese Academy of Agricultural Sciences

No. 12 Zhongguancun Nandajie

Haidian District, Beijing 100081, China

zhangyoujun@caas.cn

\section{TYLCV Infection Alters Bemisia tabaci MED (Hemiptera: Aleyrodidae) Vulnerability to}

\section{Flupyradifurone}

Baiming Liu ${ }^{1 \dagger}$, Evan L. Preisser ${ }^{2 \dagger}$, Xiaoguo Jiao $^{3}$, and Youjun Zhang ${ }^{4}$ China

${ }^{1}$ Institute of Plant Protection, Tianjin Academy of Agricultural Sciences, Tianjin 300381,

${ }^{2}$ Department of Biological Sciences, University of Rhode Island, Kingston, RI 02881

${ }^{3}$ State Key Laboratory of Biocatalysis and Enzyme Engineering, Center for Behavioral Ecology \& Evolution, School of Life Sciences, Hubei University, Wuhan, 430062, China

${ }^{4}$ Department of Entomology, Institute of Vegetables and Flowers, Chinese Academy of Agricultural Sciences, Beijing 100081, China

$\dagger$ These authors contributed equally to this work. 


\section{Abstract}

24 The whitefly Bemisia tabaci (Hemiptera: Aleyrodidae) is a major phloem-feeding pest of

25 agricultural crops that is also an important vector of many plant diseases. The B. tabaci

26 Mediterranean ('MED') biotype is a particularly effective vector of Tomato yellow leaf curl virus

27 (TYLCV), a devastating plant pathogen. While insecticides play an important role in the control

28 of MED and TYLCV, little is known about how TYLCV infection affects MED susceptibility to

29 insecticides. We conducted research addressing how MED susceptibility to flupyradifurone, the

30 first commercially available systemic control agent derived from the butenolide class of

31 insecticides, was affected by TYLCV infection. We first conducted bioassays determining the

$32 \mathrm{LC}_{15}$ and $\mathrm{LC}_{50}$ for control and viruliferous MED feeding on either water- or insecticide-treated

33 plants. We next measured several demographic parameters of control and viruliferous MED

34 exposed to either insecticide- or water-treated plants. TYLCV infection increased MED tolerance

35 of flupyradifurone: the $\mathrm{LC}_{15}$ and $\mathrm{LC}_{50}$ of viruliferous MED were double that of uninfected MED.

36 Viral infection also altered MED demographic responses to flupyradifurone, but in an

37 inconsistent manner. While the ability of TYLCV and other persistently-transmitted viruses to

38 benefit Bemisia via manipulation of host plant defense is well-known, this appears to be the first

39 example of virally-mediated changes in vector susceptibility to an insecticide.

40 Key Words

41 Insecticide, Sivanto, tolerance, Bemisia, TYLCV 


\section{Introduction}

43 The whitefly Bemisia tabaci Gennadius (Hemiptera: Aleyrodidae) is a major phloem-feeding

44 pest of both field and greenhouse crops worldwide (Stansly and Naranjo 2010). Its management

45 is complicated by the fact that $B$. tabaci contains over 30 phenotypically identical but genetically distinct cryptic species (Liu et al. 2012, Hadjistylli et al. 2016) that vary widely in traits such as

47 insecticide resistance (Chen et al. 2016, Xie et al. 2017). Bemisia tabaci Mediterranean (MED) poses a particular threat to agriculture due to its invasiveness. Since its arrival in China in 2003

49 (Chu et al. 2006), it has displaced both native and invasive B. tabaci throughout the country 50 (Teng et al. 2010).

Although Bemisia feeding can itself reduce plant growth, its primary threat to agriculture

52 occurs via its ability to transmit a wide variety of plant viruses. MED is particularly effective at

53 transmitting such viruses, and its invasion is often associated with plant disease outbreaks (Ning

54 et al. 2015). The Tomato yellow leaf curl virus (TYLCV) is a particularly damaging pathogen

55 that has caused significant damage worldwide (Jones 2003). TYLCV relies on B. tabaci as a

56 vector to spread among plants (Fereres and Moreno 2009). As a result, Bemisia- plant-TYLCV

57 interactions have been the subject of intense interest and researchers have confirmed the

58 mutualistic relationship between $B$. tabaci and the virus. It is now known, for instance, that

59 TYLCV can increase Bemisia fitness via its suppression of plant defense (Zhang et al. 2012,

60 Luan et al. 2013) and that MED benefits from feeding on TYLCV-infected hosts (Pan et al.

61 2013a, Shi et al. 2019).

62

Insecticides play an important role in an integrated pest management approach to controlling Bemisia and viral outbreaks in agricultural systems. Because the whitefly can rapidly

64 develop insecticide resistance, the continued development and deployment of novel compounds 
65 is essential for effective pest control. One such compound is flupyradifurone, the first commercially available systemic control agent derived from the butenolide class of insecticides (Nauen et al. 2015). This compound, an agonist on insect nicotinic acetylcholine receptors, differs structurally from other chemicals that target these receptors. As a result, it is effective against neonicotinoid- and pymetrozine-resistant Bemisia populations (Nauen et al. 2015).

A recent assessment of MED survival and TYLCV transmission found that while flupyradifurone rapidly killed MED and reduced TYLCV transmission by $85 \%$, treatment with the neonicotinoid thiomethoxam only reduced viral transmission by 25\% (Roditakis et al. 2017). Other work confirming the general efficacy of flupyradifurone against B. tabaci Middle EastAsia Minor 1 (MEAM1) nonetheless found a few field populations with high levels of flupyradifurone tolerance (Smith et al. 2016). While increasing insecticide tolerance in its vector would clearly benefit TYLCV and similar viruses, there is no published research assessing whether viruses can provide such benefits. Alternately, TYLCV could affect MED in a manner similar to Rickettsia, which is correlated with increased Bemisia sensitivity to a range of different insecticides (Kontsedalov et al. 2008, but see Pan et al. 2013b). Understanding how TYLCV affects the flupyradifurone tolerance of its vector is important to maximize the effective use of this important insecticide.

We report the results of two experiments exploring how TYLCV infection affected MED susceptibility to flupyradifurone (trade name Sivanto). We first determined the $\mathrm{LC}_{15}$ and $\mathrm{LC}_{50}$ for control and viruliferous MED feeding on plants treated with either Sivanto or distilled water. We calculated both $\mathrm{LC}_{15}$ and $\mathrm{LC}_{50}$ because chemical degradation and dilution gradually reduce insecticide concentrations following application (e.g., Roditakis et al. 2017),. We next measured several demographic parameters of control and viruliferous MED exposed to either insecticide- 
or water-treated plants. Although TYLCV infection has little direct effect on MED fitness (Pan et al. 2013a, Su et al. 2015), recent work found a net downregulation of detoxification enzymes in TYLCV-infected MED (Ding et al. 2019); we hypothesized that viruliferous MED would be more sensitive to Sivanto than uninfected individuals.

\section{Materials and Methods}

Plants: Tomato plants (Solanum lycopersicum L, cv. Zhongza 9) were grown individually in twoliter pots in a greenhouse with natural lighting and controlled temperature $\left(26 \pm 2^{\circ} \mathrm{C}\right)$. All plants were grown in a 10:5:1 (by volume) mixture of peat moss, vermiculite, and organic 8-8-8 fertilizer. TYLCV-infected plants were produced with injection of Agrobacterium tumefaciensmediated TYLCV clones (Shanghai isolate) at the 3-4 true leaf stage (Zhang et al. 2009). The plants were grown for four weeks post-injection to give them time to display infection-associated pathological symptoms.

Insects: The whitefly Bemisia tabaci MED (Q) was first collected in 2009 from poinsettia, Euphorbia pulcherrima Wild. (ex Klotz.), in Beijing, China. It was reared on poinsettia. In 2015, a portion of the population ( $\sim 300$ adults) was transferred to the Tianjin Institute of Plant Protection and reared on cotton plants (Gossypium herbaceum L., cv DP99B) in 80 mesh nylon insect cages $(45 \times 45 \times 60 \mathrm{~cm})$ under $26 \pm 2^{\circ} \mathrm{C}, 60 \pm 10 \% \mathrm{RH}, 14 \mathrm{~L}: 10 \mathrm{D}$ photoperiod. A viruliferous MED population was produced by transferring $~ 300$ whiteflies into a cage with four TYLCV-infected tomato plants; a parallel uninfected MED population was produced by transferring $>300$ whiteflies into a cage with four healthy tomato plants. Both viruliferous and uninfected MED were reared for two generations on their respective plants before being used for experiments. Colony purity was monitored every 2-3 generations using a DNA marker (Khasdan et al. 2005), and TYLCV infection was confirmed via PCR validation (Ghanim et al. 2007). 
112

113

114

115

116

117

118

119

120

121

122

123

124

125

126

127

128

129

130

131

132

133

flupyradifurone) was provided by Bayer Crop Science (China) Company Ltd. and diluted with distilled water to five different concentrations: $200 \mathrm{mg}[\mathrm{AI}] \mathrm{kg}^{-1}, 100 \mathrm{mg}[\mathrm{AI}] \mathrm{kg}^{-1}, 50 \mathrm{mg}[\mathrm{AI}] \mathrm{kg}^{-1}$, $25 \mathrm{mg}[\mathrm{AI}] \mathrm{kg}^{-1}$, and $12.5 \mathrm{mg}[\mathrm{AI}] \mathrm{kg}^{-1}$. For each of the five concentrations and an additional distilled water control (a total of six treatments), $200 \mathrm{~mL}$ was added to a $500 \mathrm{~mL}$ plastic spray bottle. For each concentration, one spray bottle was used to spray four tomato plants that were each at the 6-7 true leaf stage; plants were sprayed until drip-off. One day after spraying, 100 newly-emerged (within 24 hours) adult MED per plant were placed in clip cages attached to the abaxial side of both the third and fourth leaves of each sprayed plant. Clip cages were kept on for two days; the number of living and dead MED were then counted. This work was conducted in a climate-controlled chamber at $26 \pm 1^{\circ} \mathrm{C}$ and $60 \pm 10 \%$ RH with $14 \mathrm{~L}: 10 \mathrm{D}$ photoperiod.

Demographic responses of viruliferous and uninfected MED to flupyradifurone ( $\mathrm{LC}_{15}$ ):

Data from the above-mentioned experiment was used to calculate the $\mathrm{LC}_{15}$ for viruliferous MED. a solution of this concentration was sprayed on healthy tomato plants at the 6-7 true leaf stage until drip-off. Another group of healthy tomato plants was sprayed to drip-off with distilled water. After 24 hours, approximately 100 newly emerged (within one day) viruliferous or uninfected MED were attached in separate clip cages to the abaxial side of the third and fourth leaves of either a Sivanto-treated or control plant. This produced four treatments: TYLCV (uninfected, viruliferous) crossed with insecticide $\left(\mathrm{dH}_{2} \mathrm{O}\right.$, Sivanto). This work were conducted in a climate-controlled chamber at $26 \pm 1{ }^{\circ} \mathrm{C}$ and $60 \pm 10 \% \mathrm{RH}$ with $14 \mathrm{~L}: 10 \mathrm{D}$ photoperiod. Clip cages were removed after two days and the living and dead adult MED collected and counted.

Female adult longevity and first-week fecundity: Thirty female MED from each of the four treatments (=120 total) were placed individually in clip cages. Each cage was then clipped 
134 on the abaxial side of a middle leaf of an unsprayed healthy tomato plant (6-7 true leaf stage). A

135

136

137

138

139

140

141

142

143

144

145

146

147

148

149

150

151

152

153

154

155

156 total of two MED were clipped onto each plant, one per leaf, and both MED on a given plant had

the same infection status (i.e., they were both either uninfected or viruliferous). The clip cages

were checked each day for MED mortality; after one week, all surviving adults were individually

transferred to new unsprayed healthy tomato plants and the number of eggs laid during the first

week counted.

Egg-to-adult survival and developmental time: Five pairs of newly-emerged MED

(within one day; 1:1 sex ratio) from a given treatment were placed into a single clip cage and clipped onto the abaxial side of a middle leaf of an unsprayed healthy tomato plant (6-7 true leaf stage). Only one clip cage was attached to each plant. This was replicated 10 times in each of the four treatments, for a total of 40 replicates. After one day, each clip cage was opened and the adults were removed, leaving only the eggs and nymphs. Each clip cage was then inspected daily and the number of nymphs and adults recorded. Daily inspections continued until the last nymph had either entered adulthood or died.

Statistical analysis: Probit parameter estimation of the concentration-mortality response for viruliferous and uninfected MED in the six concentrations were calculated using POLO-PC (Russell et al. 1977, LeOra 1987). These parameters included $\mathrm{LC}_{15}$ and $\mathrm{LC}_{50}$ values expressed in mg[AI] kg-1 and their corresponding 95\% confidence limit (CL) along with the slopes of the probit regressions. Between-treatment differences in the mortality of viruliferous and uninfected MED were calculated using $95 \%$ CLs; $\mathrm{LC}_{15}$ or $\mathrm{LC}_{50}$ values for viruliferous and uninfected MED were considered significantly different if their corresponding 95\% CLs did not overlap.

Data on each of the demographic responses was analyzed using two-way ANOVA to assess the main effects of TYLCV (uninfected, viruliferous) and insecticide (dH2O, Sivanto) as 
157 well as their interaction. When one or more main effects or their interaction was significant at $\mathrm{p}$

$158=0.05$, Tukeys' HSD was used for means separation tests. Data on adult longevity and survival

159 was sqrt transformed before analysis. All analyses were conducted using JMP 9.0.0 (SAS 2010).

$160 \quad$ Results

161 Viruliferous MED were more tolerant of Sivanto than uninfected MED (Table 1). The

$162 \mathrm{LC}_{15}$ of viruliferous MED was more than twice that of uninfected MED (11.8 versus 5.8,

163 respectively), and the $\mathrm{LC}_{50}$ of viruliferous $\mathrm{MED}$ was almost twice as high (31.3 versus 17.3).

164 The 95\% CLs of viruliferous and uninfected MED did not overlap, meaning that the two groups

165 differed significantly in both their $\mathrm{LC}_{15}$ and $\mathrm{LC}_{50}$ values (Table 1).

166 Exposure to Sivanto (at $\mathrm{LC}_{15}$ concentration determined for viruliferous MED) marginally

167 increased adult female longevity (Fig. 1A), increased first-week fecundity (Fig. 1B) and

168 decreased egg-adult development time (Fig. 1C) in both MED groups (Table 2). In contrast, the

169 only significant main effect of TYLCV was a 28\% decrease in first-week fecundity (Fig. 1B).

170 The TYLCV*Sivanto interaction was marginally significant $(\mathrm{P}=0.067-0.085)$ for three of the

171 four variables: Sivanto had a greater impact on the first-week fecundity and egg-adult

172 development time of uninfected MED than viruliferous MED (Fig. 1B, 1C), but increased the

173 adult female lifespan of viruliferous MED more than for uninfected MED (Fig. 1A). Survival

174 from egg to adult (Fig. 1D) was not affected by either main effect or their interaction (Table 2).

$175 \quad$ Discussion

176 Contrary to expectations, we found that TYLCV did not increase MED vulnerability to

177 flupyradifurone. Instead, both the $\mathrm{LC}_{15}$ and $\mathrm{LC}_{50}$ values for viruliferous MED were significantly

178 higher than those of uninfected MED (Table 1). In three of the four demographic variables, there

179 was also a marginally significant interaction between Sivanto and TYLCV: Sivanto tended to 
180 increase adult longevity only in viruliferous MED and first-week fecundity only in uninfected 181 MED, and tended to decrease egg-adult development time only in uninfected MED (Fig.

182 1A,B,C). While the ability of TYLCV and other persistently-transmitted viruses to benefit 183 Bemisia via manipulation of host plant defense is well-known, this appears to be the first example of virally-mediated changes in vector susceptibility to an insecticide.

While our results were surprising, there have been other reports of microorganismmediated changes in insecticide susceptibility (Pietri and Liang 2018). Gut symbionts in both the 187 cigarette beetle Lasioderna serricorne (Shen and Dowd 1991) and the apple fly Rhagoletis 188 pomonella (Lauzon et al. 2003) are involved with the detoxification of natural and synthetic toxins. In contrast, the symbiotic microorganism Rickettsia increased Bemisia sensitivity to a 190 range of different insecticides (Kontsedalov et al. 2008, but see Pan et al. 2013b); later research 191 linked increases in Bemisia symbiont diversity and density to greater insecticide susceptibility 192 (Ghanim and Kontsedalov 2009). Similar results have been reported in the psyllid Diaphorina 193 citri, where infection with Candidatus Liberibacter asiaticus increased its vulnerability to several

194 insecticides (Tiwari et al. 2011). A recent review (Pietri and Liang 2018) suggested these 195 variable results may partially reflect symbiont-specific effects on both host detoxification enzymes and their immune/stress response. A transcriptomic analysis of gene regulation in

197 TYLCV-infected MED found that while TYLCV generally downregulated detoxification 198 enzymes, genes involved in both stress and immune responses were upregulated (Ding et al. 199 2019). It seems likely that some of these upregulated genes alter MED susceptibility to 200 flupyradifurone.

The negative impact of flupyradifurone revealed in the $\mathrm{LC}_{15}$ and $\mathrm{LC}_{50}$ bioassays appears 202 at odds with its equivocal effect on various aspects of MED demography. MED that survived one 
203 day of flupyradifurone exposure had slightly higher female longevity, higher first-week

204 fecundity, and a shorter egg-adult development time than MED in the control treatment. These

205 'benefits' of flupyradifurone are almost certainly an experiment artifact: a day of insecticide

206 exposure removed the weakest and/or most susceptible MED from the population that was

207 subsequently used for our demographic work. They may also reflect hormesis, a phenomenon in

208 which sublethal dosages of insecticide improve fecundity or provide other benefits to the

209 targeted insects (Cutler 2012). It is also worth noting that both uninfected and viruliferous MED

210 were exposed to flupyradifurone at the $\mathrm{LC}_{15}$ concentration determined for viruliferous MED.

211 Because the $\mathrm{LC}_{15}$ value for uninfected MED was lower than for viruliferous MED, this

212 flupyradifurone concentration was more lethal to the uninfected population than to the

213 viruliferous one. Higher rates of exposure-related mortality in our uninfected group may have

214 had the unintended effect of minimizing differences between the uninfected and viruliferous

215 groups. It should also be noted that the recommended label rate of flupyradifurone, $150 \mathrm{mg} / \mathrm{l}$,

216 was substantially higher than the concentrations we used; we chose to work with lower

217 concentrations in order to assess MED that survive initial exposure. The effect of TYLCV on

218 MED insecticide tolerance may be reduced or eliminated at these higher concentrations.

Pesticides can indirectly control insect-vectored plant diseases via their impact on vector

220 density. This control may be lessened, however, if vectors feeding on pesticide-sprayed plants

221 survive long enough to transmit TYLCV and other viruses. Viruliferous Bemisia efficiently

222 transmit TYLCV to uninfected plants. Less than two minutes of Bemisia salivation is necessary

223 to infect a healthy tomato plant (Jiang et al. 2000). As a result, thiamethoxam and other

224 insecticides that do not quickly kill Bemisia may prove inefficient at decreasing TYLCV 
225 transmission (Roditakis et al. 2017). Flupyradifurone has a higher knockdown rate than

226 thiamethoxam and is more effective at reducing TYLCV transmission (Roditakis et al. 2017).

227 Research assessing the impact of flupyradifurone on Bemisia feeding behavior is

228 necessary to understand the mechanism(s) underlying its effect on viral transmission. Aphids

229 feeding on thiamethoxam-treated plants, for example, spend less time in the sieve element phase

230 required for viral transmission to an uninfected plant (Cho et al. 2011, Stamm et al. 2013).

231 Although TYLCV increased MED tolerance to flupyradifurone (Table 1), it might still change

232 MED feeding behavior in ways that make this pesticide effective at reducing or eliminating viral

233 transmission. Alternately, TYLCV-linked increases in flupyradifurone tolerance may provide

234 viruliferous MED an advantage over uninfected individuals in pesticide-treated fields. If so,

235 insecticide application could, under some conditions, favor viral outbreaks in agricultural

236 systems (Pan et al. 2015).

237 In summary, our work found that infection with TYLCV altered the susceptibility of

238 Bemisia tabaci MED to flupyradifurone. While the mechanism underlying our results is

239 unknown, our findings suggest that viral infection may be capable of changing population-level

240 responses to current management practices. Even for novel insecticides, such interactions

241 highlight how work exploring pesticide impacts on each part of the vector-virus-plant interaction

242 can contribute to the development of effective strategies to control MED and TYLCV. 


\section{Acknowledgements}

244 This work was funded by the National Natural Science Foundation of China (31772171, 245 31401785), Tianjin Natural Science Foundation (17JCZDJC33700), Innovative research and

246 experimental projects for young researchers of Tianjin Academy of Agricultural Science 247 (201903). The authors declare that no conflict of interest exists. 


\section{References Cited}

Chen, W., D. K. Hasegawa, N. Kaur, A. Kliot, P. V. Pinheiro, J. Luan, M. C. Stensmyr, Y. Zheng, W. Liu, H. Sun, Y. Xu, Y. Luo, A. Kruse, X. Yang, S. Kontsedalov, G. Lebedev, T. W. Fisher, D. R. Nelson, W. B. Hunter, J. K. Brown, G. Jander, M. Cilia, A. E. Douglas, M. Ghanim, A. M. Simmons, W. M. Wintermantel, K.-S. Ling, and Z. Fei. 2016. The draft genome of whitefly Bemisia tabaci MEAM1, a global crop pest, provides novel insights into virus transmission, host adaptation, and insecticide resistance. BMC Biol. 14: 110.

Chu, D., Y. J. Zhang, J. K. Brown, B. Cong, B. Y. Xu, Q. J. Wu, and G. R. Zhu. 2006. The introduction of the exotic Q biotype of Bemisia tabaci (Gennadius) from the Mediterranean region into China on ornamental crops. Fla Entomol 89: 168-174.

Cutler, G. C. 2012. Insects, insecticides and hormesis: evidence and considerations for study. Dose-Response 11: 154-177.

Ding, T.-B., J. Li, E.-H. Chen, J.-Z. Niu, and D. Chu. 2019. Transcriptome profiling of the whitefly Bemisia tabaci MED in response to single infection of tomato yellow leaf curl virus, tomato chlorosis virus, and their co-infection. Front. Physiol. 10: 302.

Fereres, A., and A. Moreno. 2009. Behavioural aspects influencing plant virus transmission by homopteran insects. Virus Res. 141: 158-168.

Ghanim, M., and S. Kontsedalov. 2009. Susceptibility to insecticides in the Q biotype of Bemisia tabaci is correlated with bacterial symbiont densities. Pest Manag Sci 65: 939-942. Ghanim, M., I. Sobol, M. Ghanim, and H. Czosnek. 2007. Horizontal transmission of begomoviruses between Bemisia tabaci biotypes. Arthropod-Plant Interactions 1: 195-204. Hadjistylli, M., G. K. Roderick, and J. K. Brown. 2016. Global population structure of a worldwide pest and virus vector: genetic diversity and population history of the Bemisia tabaci sibling species group. PLoS ONE 11: e0165105.

Jiang, Y., C. de Blas, L. Barrios, and A. Fereres. 2000. Correlation between whitefly (Homoptera: Aleyrodidae) feeding behavior and transmission of tomato yellow leaf curl virus. Ann. Entomol. Soc. Am. 93: 573-579. Jones, D. 2003. Plant viruses transmitted by whiteflies. Eur. J. Plant Pathol. 109: 195-219. Khasdan, V., I. Levin, A. Rosner, S. Morin, S. Kontsedalov, L. Maslenin, and A. R. Horowitz. 2005. DNA markers for identifying biotypes B and Q of Bemisia tabaci (Hemiptera: Aleyrodidae) and studying population dynamics. Bull. Entomol. Res. 95: 605-613.

Kontsedalov, S., E. Zchori-Fein, E. Chiel, Y. Gottlieb, M. Inbar, and M. Ghanim. 2008. The presence of Rickettsia is associated with increased susceptibility of Bemisia tabaci (Homoptera: Aleyrodidae) to insecticides. Pest Manag Sci 64: 789-792.

Lauzon, C. R., S. E. Potter, and R. J. Prokopy. 2003. Degradation and detoxification of the dihydrochalcone phloridzin by Enterobacter agglomerans, a bacterium associated with the apple pest, Rhagoletis pomonella (Walsh) (Diptera: Tephritidae). Environ Entomol 32: 953-962.

LeOra (ed.) 1987. POLO-PC. A User's Guide to Probit or Logit Analysis. LeOra Software, Berkeley, CA.

Liu, S.-S., J. Colvin, and P. J. De Barro. 2012. Species concepts as applied to the whitefly Bemisia tabaci systematics: how many species are there? J. Integr. Agric. 11: 176-186.

Luan, J. B., D. M. Yao, T. Zhang, L. L. Walling, M. Yang, Y. J. Wang, and S. S. Liu. 2013. Suppression of terpenoid synthesis in plants by a virus promotes its mutualism with vectors. Ecol Lett 16: 390-398. 
Nauen, R., P. Jeschke, R. Velten, M. E. Beck, U. Ebbinghaus-Kintscher, W. Thielert, K. Wölfel, M. Haas, K. Kunz, and G. Raupach. 2015. Flupyradifurone: a brief profile of a new butenolide insecticide. Pest Manag Sci 71: 850-862. Ning, W., X. Shi, B. Liu, H. Pan, W. Wei, Y. Zeng, X. Sun, W. Xie, S. Wang, Q. Wu, J. Cheng, Z. Peng, and Y. Zhang. 2015. Transmission of Tomato yellow leaf curl virus by Bemisia tabaci as affected by whitefly sex and biotype. Sci. Rep. 5: 10744.

Pan, H., E. L. Preisser, D. Chu, S. Wang, Q. Wu, Y. Carrière, X. Zhou, and Y. Zhang. 2015. Insecticides promote viral outbreaks by altering herbivore competition. Ecol. Appl. 25: 1585-1595.

Pan, H. P., D. Chu, B. M. Liu, X. B. Shi, W. Xie, Y. Carriere, X. C. Li, and Y. J. Zhang. 2013a. Differential effects of virus on its two closely-related vectors, Bemisia tabaci B and Q. Sci. Rep. 3: 2230.

Pan, H. P., D. Chu, B. M. Liu, W. Xie, S. L. Wang, Q. J. Wu, B. Y. Xu, and Y. J. Zhang. 2013b. Relative amount of symbionts in insect hosts changes with host-plant adaptation and insecticide resistance. Environ Entomol 42: 74-78.

Pietri, J. E., and D. Liang. 2018. The links between insect symbionts and insecticide resistance: causal relationships and physiological tradeoffs. Ann. Entomol. Soc. Am. 111: 92-97.

Roditakis, E., M. Stavrakaki, M. Grispou, A. Achimastou, X. Van Waetermeulen, R. Nauen, and A. Tsagkarakou. 2017. Flupyradifurone effectively manages whitefly Bemisia tabaci MED (Hemiptera: Aleyrodidae) and tomato yellow leaf curl virus in tomato. Pest Manag Sci 73: 1574-1584.

Russell, R. M., J. L. Robertson, and N. E. Savin. 1977. POLO: A New Computer Program for Probit Analysis. Bull Entomol Soc Am 23: 209-213.

SAS 2010. JMP user's guide, version 9.0 computer program, version By SAS, Cary NC. Shen, S. K., and P. F. Dowd. 1991. Detoxification spectrum of the cigarette beetle symbiont Symbiotaphrina kochii in culture. Entomol Exp Appl 60: 51-59.

Shi, X., E. L. Preisser, B. Liu, H. Pan, M. Xiang, W. Xie, S. Wang, Q. Wu, C. Li, Y. Liu, X. Zhou, and Y. Zhang. 2019. Variation in both host defense and prior herbivory can alter plantvector-virus interactions. BMC Plant Biol. 19: 556.

Smith, H. A., C. A. Nagle, C. A. MacVean, and C. L. McKenzie. 2016. Susceptibility of Bemisia tabaci MEAM1 (Hemiptera: Aleyrodidae) to Imidacloprid, Thiamethoxam, Dinotefuran and Flupyradifurone in South Florida. Insects 7: 57.

Stansly, P. A., and S. E. Naranjo (eds.). 2010. Bemisia: Bionomics and Management of a Global Pest. Springer, New York NY.

Su, Q., E. L. Preisser, X. M. Zhou, W. Xie, B. M. Liu, S. L. Wang, Q. J. Wu, and Y. J. Zhang. 2015. Manipulation of host quality and defense by a plant virus improves performance of whitefly vectors. J. Econ. Entomol. 108: 11-19.

Teng, X., F. H. Wan, and D. Chu. 2010. Bemisia tabaci biotype Q dominates other biotypes across China. Fla Entomol 93: 363-368.

Tiwari, S., K. Pelz-Stelinski, and L. L. Stelinski. 2011. Effect of Candidatus Liberibacter asiaticus infection on susceptibility of Asian citrus psyllid, Diaphorina citri, to selected insecticides. Pest Manag Sci 67: 94-99.

Xie, W., C. Chen, Z. Yang, L. Guo, X. Yang, D. Wang, M. Chen, J. Huang, Y. Wen, Y. Zeng, Y. Liu, J. Xia, L. Tian, H. Cui, Q. Wu, S. Wang, B. Xu, X. Li, X. Tan, M. Ghanim, B. Qiu, H. Pan, D. Chu, H. Delatte, M. N. Maruthi, F. Ge, X. Zhou, X. Wang, F. Wan, Y. Du, C. Luo, F. Yan, E. L. Preisser, X. Jiao, B. S. Coates, J. Zhao, Q. Gao, J. Xia, Y. Yin, Y. Liu, 
338 J. K. Brown, X. J. Zhou, and Y. Zhang. 2017. Genome sequencing of the sweetpotato whitefly 339 Bemisia tabaci MED/Q. GigaScience 6: 1-7.

340 Zhang, H., H. Gong, and X. Zhou. 2009. Molecular characterization and pathogenicity of

341 tomato yellow leaf curl virus in China. Virus Genes 39: 249-255.

342 Zhang, T., J. B. Luan, J. F. Qi, C. J. Huang, M. Li, X. P. Zhou, and S. S. Liu. 2012.

343 Begomovirus-whitefly mutualism is achieved through repression of plant defences by a virus

344 pathogenicity factor. Mol Ecol 21: 1294-1304. 
346 Table 1: Median lethal concentration $\left(\mathrm{LC}_{15}\right.$ and $\left.\mathrm{LC}_{50}\right)$ of flupyradifurone (Sivanto) to uninfected

347 and viruliferous MED. $\mathrm{LC}_{15}$ and $\mathrm{LC}_{50}$ followed by different upper-case letters indicate that

348 uninfected and viruliferous MED are significantly different based on overlap of 95\% CLs.

\begin{tabular}{|c|c|c|c|c|c|c|}
\hline Treatment & $N$ & $\begin{array}{c}\text { Slope } \pm \\
\text { SE }\end{array}$ & $\begin{array}{c}\mathrm{LC}_{15}\left(\mathrm{mg}[\mathrm{AI}] \mathrm{kg}^{-1}\right) \\
(95 \% \mathrm{CL})\end{array}$ & $\begin{array}{c}\mathrm{LC}_{50}\left(\mathrm{mg}[\mathrm{AI}] \mathrm{kg}^{-1}\right) \\
(95 \% \mathrm{CL})\end{array}$ & $X^{2}(\mathrm{df})$ & $\begin{array}{c}\mathrm{P} \\
\text { value }\end{array}$ \\
\hline Uninfected & 478 & $\begin{array}{c}3.64 \pm \\
0.39 \\
\end{array}$ & $5.78(3.72-7.82) \mathrm{A}$ & $\begin{array}{l}17.33(14.08-20.48) \\
\text { A }\end{array}$ & $\begin{array}{c}1.61 \\
(3)\end{array}$ & 0.66 \\
\hline Viruliferous & 476 & $\begin{array}{c}4.07 \pm \\
0.36\end{array}$ & $\begin{array}{l}11.75(8.91-14.44) \\
\text { B }\end{array}$ & $\begin{array}{l}31.33(27.22-35.82) \\
\text { B }\end{array}$ & $2.4(3)$ & 0.49 \\
\hline
\end{tabular}

Table 2: Results of ANOVA assessing the impact of TYLCV infection, Sivanto exposure, and

352 their interaction on MED demographic variables.

Egg-adult

Female longevity First week fecundity developmental time Egg-adult survival

(d) (\# eggs)

(d)

$(\%)$

\begin{tabular}{|c|c|c|c|c|c|c|c|c|c|c|c|c|}
\hline \multirow[b]{2}{*}{ Treatment } & \multicolumn{3}{|c|}{ (d) } & \multicolumn{3}{|c|}{ (\# eggs) } & \multicolumn{3}{|c|}{ (d) } & \multicolumn{3}{|c|}{$(\%)$} \\
\hline & $F$ & $d f$ & $P$ & $F$ & $d f$ & $P$ & $F$ & $d f$ & $P$ & $F$ & $d f$ & $P$ \\
\hline $\mathrm{TYLCV}^{\dagger}$ & 0.43 & 1,101 & 0.513 & 15.71 & 1,101 & $<0.001$ & 0.86 & 1,18 & 0.364 & 1.03 & 1,18 & 0.324 \\
\hline Sivanto & 3.55 & 1,101 & 0.063 & 10.24 & 1,101 & 0.002 & 7.26 & 1,18 & 0.015 & 0.31 & 1,18 & 0.586 \\
\hline TYLCV*Sivanto & 3.43 & 1,101 & 0.067 & 3.18 & 1,101 & 0.078 & 3.34 & 1,18 & 0.085 & 0.97 & 1,18 & 0.338 \\
\hline
\end{tabular}




\section{$354 \quad$ Figure Legends}

355 Figure 1. Bemisia tabaci MED feeding on Lycopersicon esculentum. Mean \pm SE values for the 356 demographic variables A) Female longevity (days); B) Eggs per female over one week; C) Egg-

357 adult development time (days); and D) Egg-adult survival (\%). Light gray bars: uninfected MED;

358 dark gray bars: viruliferous MED. Unstriped bars (S-): plants sprayed with distilled water;

359 striped bars (S+): plants sprayed with $11.75 \mathrm{mg}[\mathrm{AI}] \mathrm{kg}^{-1}$ Sivanto ( $\mathrm{LC}_{15}$ for viruliferous MED).

360 Different upper-case letters above bars indicate significant differences (Tukeys' HSD with $\alpha=$

$3610.05)$; in figure $1 \mathrm{D}$, there were no significant between-treatment differences. 
Figure 1.

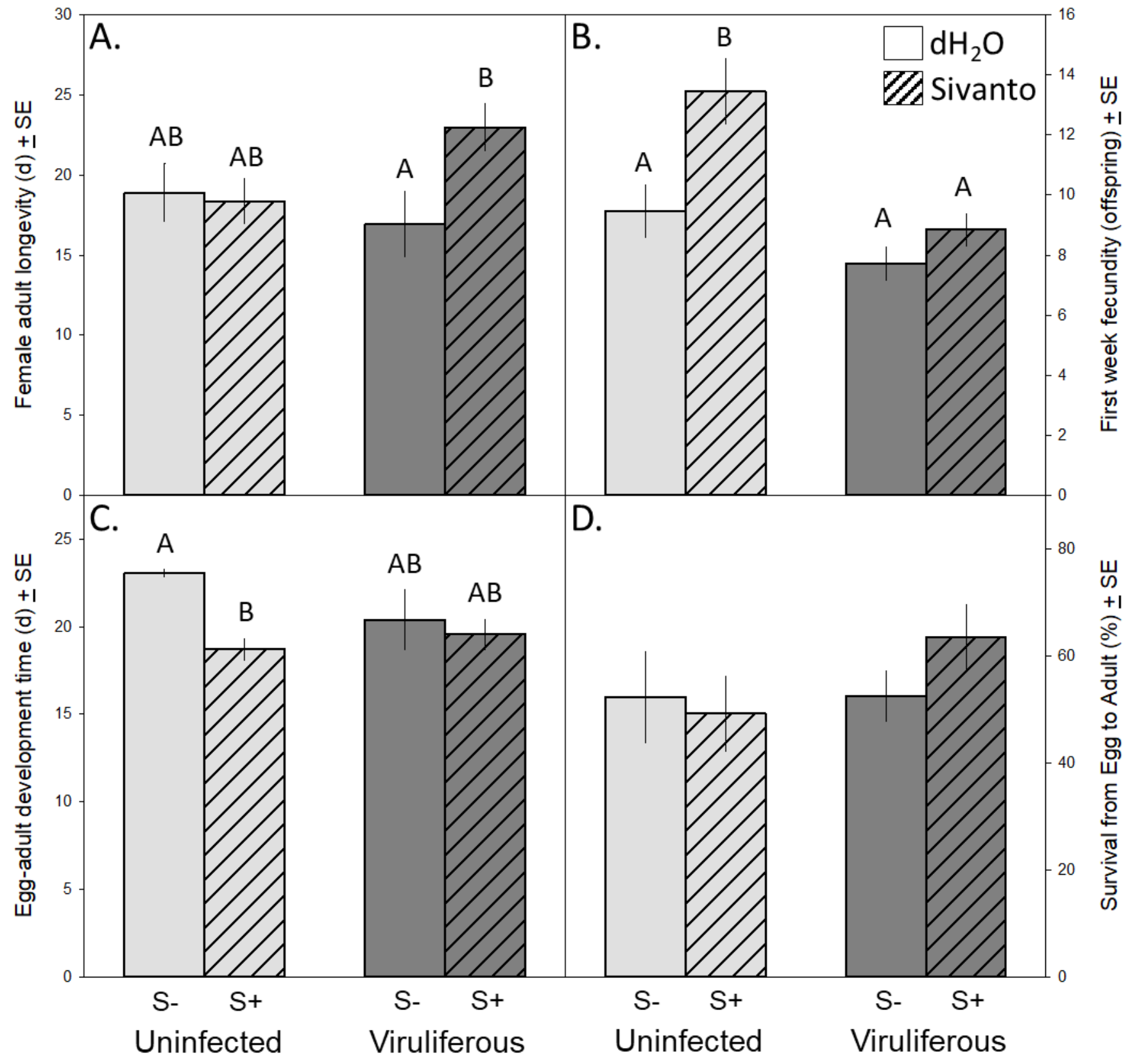

